\title{
The Body Out-of-Bounds: Trauma, Corporeality and Representation in Marina de Van's Ne te retourne pas/Don't Look Back (2009)
}

Romain CHAREYRON

Washington State University

In his book Cinema 1, Gilles Deleuze mentions that one of the specificities of the projection screen is to give a common measure to the different objects caught by the eye of the camera, when these objects do not share any common traits in the real world. In so doing, cinema shatters the concept of natural perception by presenting as unproblematic a visual scale that, in any other given context, would seem inconceivable:

$[\ldots]$ the screen, as the frame of frames, gives a common standard of measurement to things which do not have one - long shots of countryside and close-ups of the face, an astronomical system and a single drop of water - parts which do not have the same denominator of distance, relief or light. In all these senses the frame ensures a deterritorialization of the image.

(Deleuze 1986: 14-15 - my emphasis)

Deleuze appears to consider the cinematic image to be a distortion of reality: if the frame is what gives its unity to the film and constitutes "the logic of what we see on the screen" (Buchanan 2006: 140), its composition (i.e. the succession of images that constitute the narrative) represents the utmost violation of what we commonly deem "true" or "realistic". Steven Shaviro further exemplifies this dichotomy when he points out the dual nature of film images as they present themselves to the viewer: 
The antinomy of cinematic perception is the following: film viewing offers an immediacy and violence of sensation that powerfully engages the eye and the body of the spectator; at the same time, however, it is predicated on a radical dematerialization of appearances.

(Shaviro 1993: 26)

These remarks make it clear that the film image is first and foremost characterized by its ambivalence: when watching a film, we are entailed to think of what is taking place on screen as "natural", while the flow of images we see acts as a complete disruption of our sense of verisimilitude. In other words, we believe in cinema despite our own will. It is the frame of the screen that brings together these fragmented visions of which the film is composed and enables the viewer to experience the fictional world without questioning its existence.

Marina de Van's Ne te retourne pas/Don't Look Back (2009) disrupts the suspension of disbelief at the heart of most film-viewing experiences by engaging the spectator with images that progressively do away with cinema's mimetic concerns in order to produce a reality that cannot be traced back to any model in the outside world of human experience. As was already the case with her previous film Dans ma peau/In My Skin (2001)', de Van's mise-en-scène in Ne te retourne pas confronts the viewer with discomfiting images of physicality that dislodge the logic of representation and ask for a physical and visceral engagement from the audience. By presenting us with dysfunctional bodies that are no longer safeguarded by social or behavioral concerns, de Van's cinematography challenges one of cinema's primary conventions, that consists in thinking of the body "as primarily the means for character formation [...] and, crucially, the site of readable behavior from which derives overt psychology" (Palmer 2006: 175). In so doing, her films rely heavily on the expressive qualities of the filmed body to affect the representation as well as our response to what is presented on screen ${ }^{2}$.

Ne te retourne pas revolves around Jeanne (Sophie Marceau/Monica Bellucci), a respected biographer struggling to write her first novel, whose life is turned upside-down by a series of inexplicable and disturbing changes. These changes are all the more distressing to her, as she seems to be the only one to notice them. What first appeared as a sign of tiredness gradually takes on more traumatic proportions as she eventually cannot recognize the apartment in which she lives or her own family members. Even her body begins to transform, revealing to her the face and features of another woman ${ }^{3}$. 
Although the film was divisive and underwent a severe backlash from critics and audiences alike ${ }^{4}$, this article posits that Ne te retourne pas remains within the director's visual and narrative concerns as an auteur, as it allows her to further interrogate the human body as a malleable and interpretative surface that the cinematic apparatus can deform and transform in order for the viewer to rediscover the affective powers of the body and its ability "not only of receiving, but also of acting upon, the structuration of meaning in the cinema" (del Río 2008: 2).

This article discusses how de Van's film achieves a visual regimen wherein the spectator's gaze is dispossessed from its ability to master the onscreen world. By choosing to mimic the main character's growing psychological distress, the film opts for an aesthetic of bodily fragmentation and distortion, where the spectator can no longer hope for any fixed or pre-established meaning to be found within the representation. Jeanne's subjectivity, I argue, comes to regulate our perception of the film's events, as the mise-en-scène works to make the fictional space one of boundless possibilities, from a corporal and visual perspective. By using sensation as its organizing principle, the film relies on seeing and feeling bodies (i.e. the filmed body and the body of the audience) to create a meaning that confronts the spectator at the affective rather than the cognitive level. In so doing, the film denies the body its usual representational qualities to point out to its onscreen presence as being "an assemblage of forces or affects that enter into composition with a multiplicity of other forces or affects" (del Río 2008: 3).

De Van's aesthetic ambitions are especially striking in the opening sequence of the film, where we see Jeanne getting out of the bathtub and applying lotion and makeup to her body and face. The whole sequence is shot in a series of close-ups and inserts, so that her body never appears as a whole, but is instead captured in a succession of tableaux, each one displaying a different bodily scenario: we see Jeanne applying lotion onto her face, brushing her hair, or applying eyeliner and lipstick. The representation pays a specific attention to surfaces and reflections, as most of the sequence is seen through mirrors, whether it is the large one hanging over the washbasin, the small ones on each side of the cabinet, or the even smallest ones embedded in the bathroom tiles. We also notice a particular emphasis on the smooth and reflective surfaces of objects, with a camera that lingers on the chromes of the bathroom furniture or the polished surfaces of vases and bathroom utensils.

By presenting Jeanne's body on an ever-changing scale that disrupts our sense of unity, the mise-en-scène uncovers the film's desire to make 
the audience experience a de-realized representation of the human body in order to "prob[e] its nature as material substance" (Palmer 2006: 175). Indeed, the inserts on Jeanne's arm and forearm, or on her lips and her eye act as the visual antithesis of the medium shots of her bust or legs as we see them caught in the secondary frames of the mirrors. This fragmented and out-of-scale representation participates in the establishment of a body "out-of-bounds", that is, a body that has been figuratively dismembered by the camerawork, so that meaning is no longer achieved through the unproblematic, true-to-nature presence of the human figure, but rather emerges from its unstable and polymorphic nature.

The film invites us to understand the body through our senses, rather than by appealing to our intellect or rational mind. The sensuous quality of these images is attained by the combined work of lighting and framing; the warm and ochre light reveals the softness and silk-like quality of the skin, while the close-ups and inserts highlight the skin's complexion in the minutest details. Moreover, each shot captures the body in a variety of movements, as we see Jeanne either vigorously brushing her teeth and her hair, or delicately applying lotion to her face and eyeliner under her eyes. In so doing, the film summons the body as a gathering of intensities rather than a predetermined form.

What the opening sequence exemplifies is the transformational capacities of the body inasmuch as:

[...] the body and its senses disrupt the fixity of the conscious ego by inserting themselves as a third, indeterminate term into the equation. The self that emerges from such discourses is more evanescent, more fleeting than the self of modernity. It consists not of fixed points of reference but of sites of intensities and instances of sensual experience that cut across the usual coordinates of time and space.

(Elliott 2011: 3-my emphasis)

The film's denial of bodily unity is also rendered through a de-centering of the human figure. In most of the shots, the various body parts caught by the camera constantly appear at the edges of the frame: we see Jeanne's neck at the right of the frame or the reflections of her bust at the bottom left corner of the frame. The two shots capturing her face are also very telling in this respect, as we only catch sight of Jeanne through her reflection on the fogged up mirror over the washbasin, so that it is impossible to clearly make out her facial traits. While being overtly present through the various images reflected on the different types of secondary frames, the body is simultaneously rejected outside the center of the frame, as the latter seems to have been "hollowed out" of any human presence. 
In terms of rhythm, the entire scene is built on a tension between the frame and the representation, where the fixity of the projection screen is at odds with the frenzy of images that are projected onto it. This deregulation of natural perception echoes Deleuze's "dynamic" conception of the frame. For Deleuze, understanding the frame in terms of its dynamic qualities means that the existence of the onscreen body is not contingent upon the frame, but the other way round:

In any case framing is limitation. But, depending on the concept itself the limits can be conceived in two ways, mathematically or dynamically: either as preliminary to the existence of the bodies whose essence they fix, or going as far as the power of existing bodies goes.

(Deleuze 1986: 13 - my emphasis)

For Deleuze, the image is shaped by the limitless capacities of the body, so that the inescapable physical limitation of the frame does not correspond to a lessening of the body's ability to transform itself. Rather than marking the fictional space as a closed one, the dynamic conception of the frame points out to what goes on beyond this visual limitation. Since the transformative nature of the body can never be actually "framed", it is only by hinting at its semantic instability that the film unfurls a space that is constantly reshaped in order to echo the body's transformations. The drastic metamorphosis of Jeanne's body that happens midway through the film marks a new step towards the exploration/exploitation of the transformative capacities of the human body by the cinematic apparatus, together with a desire to further deterritorialize the meaning of images. In the scenes presenting Jeanne's transformation, de Van confronts the viewer with a series of arresting images that depict how the character's slow descent into paranoia, and her inability to differentiate what is real from what is not, find their visual translation at the surface of her body. To signify the invisible forces at play, de Van uses the visual technique of morphing, so that the spectator can witness Jeanne's facial traits being distorted and her face progressively transforming into someone else's. It is precisely through the duration of the transformation process that the film makes its most powerful statement regarding the ability of the film image to convey meaning at the affective level rather than at the representational level. Indeed, as the surface of the body becomes the privileged medium to display the forces that inhabit Jeanne, we need to stop considering the body in representational terms ("what does it represent?") but rather in affective terms ("what does it express?"). In the film, the body connects with the spectator, not on the basis of its representational qualities, but 
because of the sensations it comes to embody and display. In what follows, I discuss how the mise-en-scène effectively causes the spectator to sense these forces and "to actualize what is merely virtual in the frame" (Abel 2007: 7).

The affective powers of the body and their ability to (de)regulate the representation are especially significant in the scene where Jeanne, in a moment of increased panic, rushes to see her mother, who is gambling at a casino. While Jeanne waits for her mother to play her hand, we see her face suddenly transforming and distorting itself, visibly causing her pain. The soundtrack and the staccato of the violins heighten the feelings of suffering and panic felt by Jeanne. The whole transformation process is captured in a close-up, allowing the viewer to witness each twitch and convulsion of the face. The film makes visible the powerful and conflicting forces at work within Jeanne, using the surface of the skin as the translator of the character's deepest feelings.

However, it would be misleading to understand the body in purely representational terms here, as the film is primarily interested in conveying the violence of the sensation, rather than giving a logical explanation for it. This shift is exemplified by the symbolic transformation operated by the body, from a normative to an affective structure. While the former corresponds to a body that conforms to social and cultural norms, the latter characterizes a body whose presence on screen can never be attached to any predetermined behavioral pattern. The affective body is never static and can never be assigned a specific role within the narrative, as it only exists "through a process of self-modification or becoming" (del Río 2008: 3 ). An observation made by Elena del Río on the distinction between the concepts of "emotions" and "affect" holds a valuable clue to our understanding of the body in this scene. Del Río connects emotions with the ritualized way bodies are expected to perform in a given context, while she sees affect as corresponding to bodies that have ceased to conform to pre-established social or cultural schemes: "while emotion refers to habitual, culturally coded, and localized affects (such as a character's sadness or happiness), affect proper coincides with the actor and the film's openness to often anomalous, unexpected, and always expansive expressions of emotions" (del Río 2008: 10).

The shift from a normative, emotion-driven body to an affective body is at the heart of the representation in the scene at the casino. When Jeanne enters the place, we see her searching for her mother and then holding her tight, shaken to the core by the inexplicable changes she has happening to her. The feelings of fear and despair she expresses here are a logical 
and understandable reaction, being confronted with an abnormal and disturbing situation. They correspond to culturally coded emotions that exist outside the narrative. Consequently, the body performs according to a "grid" of human behavior with which the spectator easily connects and sympathizes. This corresponds to the normative function of the body. However, once Jeanne starts experiencing profound and overwhelming waves of panic while she is waiting for her mother, the feelings that take hold of her are so strong and violent that they bypass the representation's requirements for verisimilitude.

What we see upon witnessing the transformation of Jeanne's face is a body in the process of becoming, passing from one state to another, and whose essence cannot be circumscribed. This corresponds to the affective body. In the scene under discussion, the affective body is first characterized by the disorganization of its movements, as Jeanne's face twists and convulses in unnatural ways and she frantically touches it in order to understand what is happening. The soundtrack's focus on Jeanne's panting and heavy breathing also reinforces the idea of bodily disorder and the loss of control Jeanne is experiencing. This shift in our perception of the filmed body illustrates how the film breaks away from traditional storytelling by opening up its narrative to the powers of the affective body. It does so by producing images that cease to have a clear representational purpose, as they stop sharing any common traits with an external reality. Put in a different way, if images can never completely do away with representational constraints, it is still possible for these very images to create a meaning that is no longer ruled by logic, but instead corresponds to the unpredictable, unrestricted powers of the affective body.

As this analysis wished to point out, Ne te retourne pas constitutes a significant step in Marina de Van's approach of the filmed body, as her mise-en-scène works to reveal how the latter can impact on the image as well as our response to it. By choosing to convey the life-altering power of the sensations felt by Jeanne, de Van is mainly interested in capturing the forces that go through the woman's body and make us sense the intensity of these forces. In so doing, she openly departs from French cinema's interest in realism and the chronicle of everyday life (Vasse 2008: 135138), as she uses the surface of the skin and its malleability to bypass the requirements for verisimilitude and to express emotions and feelings that supersede the need for logic. Even though the narrative eventually provides the viewer with an explanation for Jeanne's growing unease, this analysis wanted to draw attention to the non-representational qualities of the film in 
its desire to open up a space within the fiction where Jeanne's subjectivity could be expressed. De Van resorts to the affective powers of the body to translate Jeanne's troubled personality and her subsequent quest for meaning because of affect's endurance in front of normative discourses:

$[\ldots]$ affect - sets of forces that critical language has not yet been able to encounter on their own terms without reducing them to the more familiar discourse of representation and judgment - is the proper name for that which largely remains unknown.

\section{(Abel 2007: 57)}

Through its depiction of "the revolt of the body" (Shaviro 1993: 130), Ne te retourne pas puts the viewer in contact with a frenzied world of images where the gaze is dispossessed from its usual supremacy over the onscreen world. The visual excess that defines the film's aesthetic participates in a heightening of our senses and profoundly destabilizes our routinized ways of receiving and decoding film images. De Van's film succeeds in actualizing the invisible forces sustained by the body, allowing the viewer to see the world with new eyes.

\section{Notes}

1. De Van's first feature film Dans ma peau focused on a young woman's downward spiral - Esther, played by de Van herself - as she starts practicing self-cutting and self cannibalism. For more information on this film, see my article "Horror and the Body: Understanding the Reworking of the Genre in Marina de Van's Dans ma peau (2001)", Imaginations: Journal of Cross-Cultural Studies - Scandals of Horror 4.1 (2013): 70-81.

2. Throughout her filmography, Marina de Van has always displayed a particular interest in revealing the hidden and unmediated forces that inhabit the seemingly domesticated body of modern culture. De Van's films state that there is no truth to be found behind the world created by fiction and her mise-en-scène works to reveal the body's ability to bypass the limitations imposed by representation and the inevitability of verisimilitude in order to become "a site of reception" (Elliott 2011: 25) that generates meaning through the sensations it embodies.

3. As we learn at the end of the film, Jeanne's delirium is rooted in childhood trauma: Jeanne's real name is Rosa Maria. She was originally born in Italy and, as a child, befriended Jeanne, a young French girl her age. One day, Rosa Maria accompanied Jeanne and her parents on a road trip and they got into a car crash that killed Jeanne. By some inexplicable turn of events, Rosa Maria came out of the accident convinced that she 
was Jeanne and the grieving couple ultimately adopted her. No one ever spoke of that tragedy again, and the physical transformations Jeanne now witnesses on her body as well as on other members of her family are the manifestations of the repressed past invading her adult life.

4. http://www.allocine.fr/film/fichefilm-110128/critiques/presse/ (consulted 01/28/14)

5. Touch is especially significant in this scene, as it crystalizes the tension between the normative and the affective body. Jeanne's gesture that consists in touching her face is the normative body expressing itself and trying to understand and take control over the unsettling bodily manifestation of the affective body. In his book on the primacy of touch, Mark Paterson explains that touch has long been regarded as the primary vehicle for communicating the immediacy and the tangibility of experience: "At least in Western industrialized cultures, such attitudes maintain the sensory stereotype whereby vision is predominant, is distanced and even deceitful, whereas touch seems more intimate, reassuring and proximal [...] touch is associated with verification, the connotations of tangibility being solid, foundational, undeceiving." (Paterson 2007: 5).

\section{Works cited}

Abel, Marco. Violent Affect: Literature, Cinema and Critique After Representation. Lincoln: University of Nebraska Press, 2007.

Buchanan, Ian. "Is a Schizoanalysis of Cinema Possible?" Cinémas: revue d'études cinématographiques/Cinemas: Journal of Film Studies 16.2-3 (2006): 116-145.

Deleuze, Gilles. Cinema 1: The Movement-Image. Trans. Hugh Tomlinson and Barbara Habberjam. Minneapolis: The University of Minnesota Press, 1986.

Del Río, Elena. Deleuze and the Cinemas of Performance: Powers of Affection. Edinburgh: Edinburgh University Press, 2008.

Elliott, Paul. Hitchcock and the Cinema of Sensations. Embodied Film Theory and Cinematic Reception. New York \& London: I.B. Tauris, 2011.

Palmer, Tim. "Under Your Skin: Marina de Van and the Contemporary French cinéma du corps" Studies in French Cinema 6.3 (2006): 171-181.

Paterson, Mark. The Senses of Touch. Haptics, Affects and Technologies. Oxford \& New York: Berg, 2007. 
Shaviro, Steven. The Cinematic Body. Theory out of Bounds. Minneapolis: The University of Minessota Press, 1993.

Vasse, David. Le Nouvel âge du cinema d'auteur français. Paris: Klincksieck, 2008.

\section{Film}

Ne te retourne pas/Don't Look Back, directed by Marina de Van (2009; MPI Home Video, 2010), DVD. 